\title{
Research on SME Intellectual Property Administrative Standardization
}

\author{
Tang Libo*
}

Department of Business and Administration, Yantai Nanshan University, Yantai, Shandong, 265713, China

\begin{abstract}
With the rapid development of science and technology, the process of economic globalization has been accelerated, intellectual property competition heats up, which becomes the key to the development of enterprise management, competition and restricting factors in the modern economic environment. Enterprise must take both with international laws and regulations system, and can effectively protect the interests of the market of intellectual property management strategy for long-term development. Through summing up chinese enterprise intellectual property management present situation, in accordance with the national "standard of enterprise intellectual property management" of the specific requirements, this paper builds the whole process of enterprise operation and management model of intellectual property standardization management, to establish a scientific management processes and system for enterprise management framework to provide the reference.
\end{abstract}

Keywords: Intellectual property administrative, SME, standardization.

\section{INTRODUCTION}

Social informatization level continuously jumped in recent years. The Chinese enterprises were profoundly affected by economic globalization. In different sectors of the economic and trade activities, there were more and more friction of IPR protection between China and the rest of the world. Especially foreign multinationals make IPR for commercial competitive weapons, containing the rapid development of China's enterpris, which ot only causes serious economic losses to the enterprise development, and also have a negative impact on Chinese enterprises "going out" strategy of overseas. Enterprise is the main body of the implementation of the national and regional intellectual property strategy, to establish an effective intellectual property management system has become a modern enterprise management must abide by the rules of the game. As the domestic market and the government pay more and more attention on IPR, a batch of normative documents such as Rules of Enterprise IPR Management were formulated and promulgated in 2013[1]. There are a large number of SME, which possess strong innovation ability. In the process of scale and intensive development, Enterprises must be fully prepared to deal with IPR of the non-tariff barriers. Chinese enterprises should take the intellectual property management standardization construction actively, lay a sound foundation for long-term stable development, economic transformation and upgrading.

\section{THE NECESSITY FOR ENTERPRISES TO STRENGTHEN THE CONSTRUCTION OF INTEL- LECTUAL PROPERTY MANAGEMENT STAN- DARDIZATION}

Standardization management is a sign of modern management, the national IPR management standardization is to meet the new need of the development, and to bring government's macroeconomic management more in line with the market economy [2], which creates a good environment for the innovation of the knowledge economy development, increases competitiveness for enterprises to provide highquality intellectual property services, ensure the healthy growth of SME.

\subsection{Standardization Management Meaning and Function}

Standardization is the highest form of institutionalization, applicable to the production, development, design, management and so on several aspects. Standardization management refers to the production and business operation and management for the enterprise within the scope of optimal order, to the actual or potential problem set the rules [3]. The standardization of enterprise management, including a set of can compliance with government laws and regulations, market industry standards such as external standard, and can match their own management idea, advocated by cultural characteristics such as internal standard of basic management system.

The implementation of standardized management plays an important role in enterprises, strictly implement standard constraints of production and business operation activities, is a can make the enterprise products occupy the dominant position in the market competition, thus effectively ensure corporate profitability; 2 it is to make the enterprise product quality in such aspects as function, safety, hygiene, environmental protection standards, to meet the consumption demand of consumers continue to improve, ensure fully safeguard consumers' legal rights; Three is authentication technology scale, industrialization index effectively, lay the cornerstone of the development of the independent IPR has been a steady innovation, promote the effective transformation of research and development and technology innovation achievements. Through constant play a role in market competition, the standardization management directly affect the enterprise development, has a vital important role. 


\subsection{The Meaning of Intellectual Property Management}

Analysis from the point of view of economy, intellectual property management is to point to to realize the maximization of the value of intellectual property work to standardize enterprise's IPR as the means, play its role in promote the enterprise independent technological innovation, the enterprise can more effective intellectual property creation, capture, maintenance, use and management, and IPR of the enterprise activities to conduct a comprehensive, system, scientific planning, organizing, leading and controlling a series of management activities [4].

Intellectual property management run through the entire course of enterprise innovation project, research and development. Within the enterprise, the competent department of intellectual property management needs to establish a system and strictly implement the relevant laws and regulations, under the guide of management tasks, effectively mobilize enterprise department each system to coordinate human, material, finance and information, and other important resources, which closely linked with enterprise production and business operation and development of each link and each aspect. Look from external, intellectual property management system needs to keep a long-term frequent interaction with the government, the outside world intellectual property services, commercial consultancy services, and related enterprises. It is necessary to feedback to enterprise leadship in time.

\subsection{The Meaning of Enterprise Intellectual Property Management Standardization}

Into the era of knowledge economy, global trade integration to speed up and the protection of IPR gathers momentum, the enterprise competitives more intense. As important strategic resources, IPR is the core of a country and region to participate in international competition. Strengthen the ability of IPR creation, utilization, protection and management, is an important way to promote its economic development and improve the core competitiveness. Enterprise intellectual property management standardization, is to preset for enterprise intellectual property management activity basic process, and control key points of the elaborating management of intellectual property work, which can effectively reduce the blindness and disorder phenomenon in management [5]. In intellectual property competition of economic globalization environment, SME are faced with the opportunities and challenges coexist. On the one hand, competition for intellectual property rights and limitation goes on, SME must have good ability of IPR management, otherwise it is difficult to adapt to long-term cruel enterprise competition, on the other hand, through the implementation of "the enterprise intellectual property management regulations", corporate management has to strengthen the consciousness of intellectual property management and improve the intellectual property management standardization, systematization and continuity [6], which promoted the enterprise market competition ability and sustainable development ability directly as shown in Fig. (1).

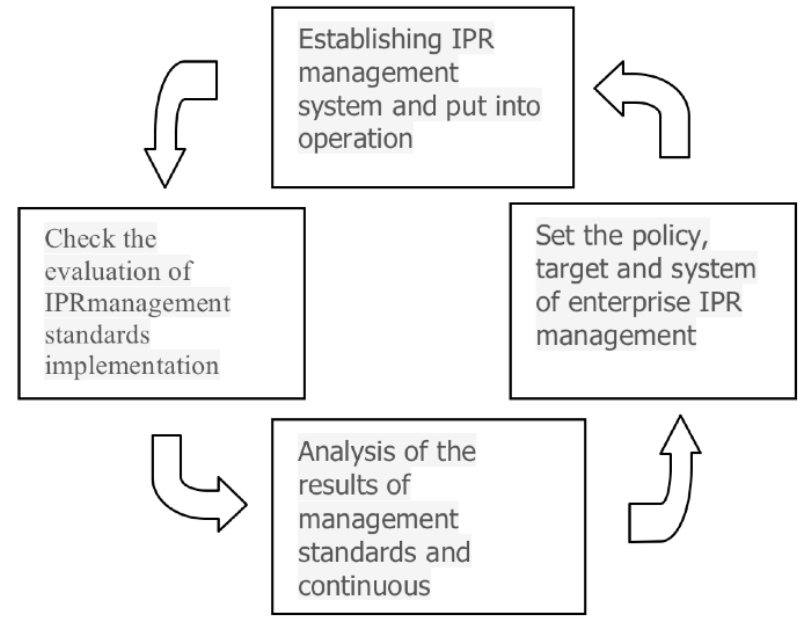

Fig. (1). Enterprise intellectual property management standardization PDCA mode.

The popular enterprise intellectual property management standardization system is on the basis of ISO9000 series standards and OHSAS18000 series authentication standards, in view of the enterprise research and development, production, marketing, cooperation of different stages, which takes loop dynamic management mode: Plan-Do-Check-Act (PDCA) [7]. By means of optimizing management standard, improving the management process framework continuously, it formes a harmonious and unified enterprise interior various intellectual property management system management specification requirements and work content.

\section{CHINESE SME INTELLECTUAL PROPERTY MANAGEMENT STATUS}

Under the stimulus of policy incentives and market requirement, chinese technology talents are increasing, and the cooperation and exchange between enterprises gradually deepen in recent years, which makes ownership of IPR in China is growing rapidly as shown in Table $\mathbf{1}$.

\subsection{Good Aspects}

As the government and enterprises to protect IPR management consciousness distinct enhancement, enterprise intellectual property management level steady rises, and there are a lot of useful experience.

(1) Intellectual property management consciousness enhancing. Under the fierce market competition situation, enterprise pay more attention to strengthening innovation ability by increasing in $\mathrm{r} \& \mathrm{~d}$ investment and practicing whole course administration. from the perspective of IPR to the creator and users, Enterprises' active management of internal IPR consciousness raises. At the same time, due to infringement of IPR, legal disputes increase rapidly, enterprises have to deal with the legal rights more rigorously on the purpose of protecting IPR effectively.

(2) The level of intellectual property management improve. On the market, the enterprise generally strengthened the management of IPR. Directional introduction of professionals proficient in intellectual property management, explicitly granted the function of intellectual property 
Table 1. IPR In 2011-2013 annual statistics inside and outside.

\begin{tabular}{|c|c|c|c|c|c|}
\hline Year & The State of IPR & İnvention Patents & Utility-Model Patents & Industrial Design & Total \\
\hline \multirow{2}{*}{2011} & Provisional Patents & 526412 & 585467 & 521468 & 1633347 \\
\hline & Patent Licenses & 172113 & 408110 & 380290 & 960513 \\
\hline \multirow{2}{*}{2012} & Provisional Patents & 652777 & 740290 & 657582 & 2050649 \\
\hline & Patent Licenses & 217105 & 571175 & 466858 & 1255138 \\
\hline \multirow{2}{*}{2013} & Provisional Patents & 825136 & 892362 & 659563 & 2377061 \\
\hline & Patent Licenses & 207688 & 692845 & 412467 & 1313000 \\
\hline
\end{tabular}

management departments within the enterprise, and grope for the supporting system of security management measures, and establish their training compound talents will intensify training of staff related special knowledge and regulations, makes enterprise intellectual property level actually improved.

\subsection{Shortcomings}

Comparing the patent application, to accept the amount of data, the growth rate of patent licenses is less than the growth rate of provisional patents. It shows that SME's innovation management level of IPR is lack of power from the side, although innovation ability strengthens in china. In the research, it is found that most of SME intellectual property management level is still low, lack of effective integrated management system. It is not only lack of long-term strategic planning, but also rare to establish effective management measures. Active management consciousness is not strong, and internal management is confusion.

(1) Lack of management excellence. Through the actual visit, the survey found that quite a number of SME management realize the importance of IPR to the enterprise longterm development, there is a clear consciousness of property strategy. In the specific management practice, intellectual property management isn't into the whole process management of the enterprise, but to submit the complete material, fulfill the formalities more simply, Which is in a passive position. Corporate management did not seize the essence of intellectual property management. It is better to adjust its overall position in the overall management framework, use in the enterprise innovation research and development, production and marketing of each link, which helps the enterprise improve its competition, development and transformation as Fig. (2).

(2) Lack of powerful competent department. Due to the SME scale and resource constraints, most enterprises don't divide IPR management work. In subsequent development, although the enterprise pay more attention on the application and maintenance of IPR management and the development, but the majority of management are worked by employees from other internal department. Although some enterprises set up independent IPR department, the intellectual property management experience of professionals are still few. The lack of professional ability and organizational capability limits the enterprise intellectual property management level

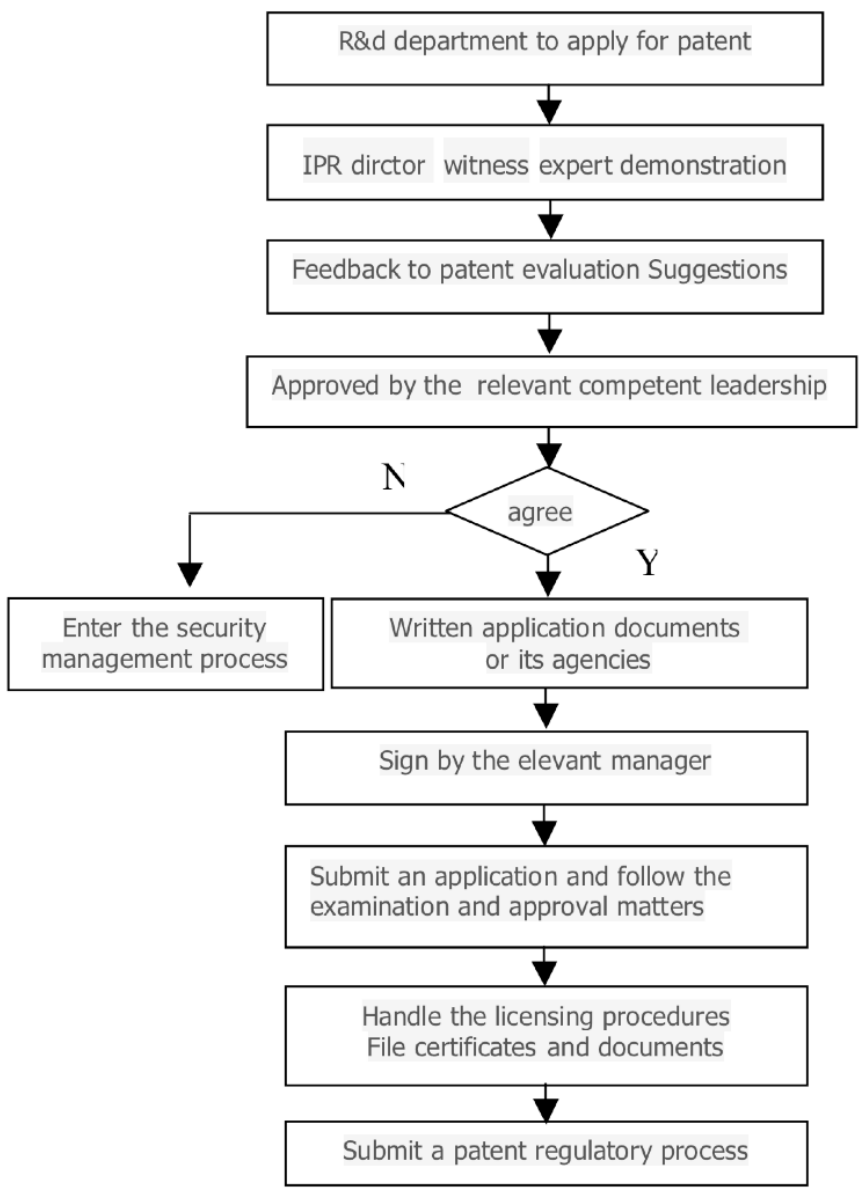

Fig. (2). An application for a patent for flow chart.

seriously. When the product maintenance payment relating to special declaration specification, and cope with problems such as infringement, enterprises are difficult to efficient manage technology, legal, financial and other links on the specific transaction, which is easy to cause irreparable damage to the enterprise.

(3) Lack of scientific coordination mechanisms. In fact, intellectual property management is complicated and systematic, which not only needs strong management organization, more need to perfect the rules and regulations to ensure the execution. In application, maintenance, use and transaction process of IPR, there is lack of a matching operation and supervision mechanism. Normalization of patent application 
and maintenance involves multiple departments, it is better to carry out the process under the guidance of IPR competent department, management is relatively simple. But when it comes to infringement of property rights of legal disputes in the process of litigation, loose, chaotic mechanism often leads to IPR management responsibility, which is shuffled, and be difficulty of proof. Part of the IPR disputes in china, there are quite a few is due to the lack of confidentiality mechanism, which is unable to implement effective protection of commercial confidentiality IPR, and leads to the loss of competitive advantage. In addition, many enterprises are lack of rewards and punishment mechanism in the protection of intellectual property rights, which is also the important cause that leads to the intellectual property rights management stagnate. On the one hand, lacking of positive encouragement for a long time, it makes the staff unimpassioned and indifferent on intellectual property management. On the other hand, lacking of discipline, it makes the staff decline of responsibility and conscientiousness.

The above problems will affect the SME intellectual property management, which are the important reasons of limiting the core competitiveness improve.

\section{SME INTELLECTUAL PROPERTY MANAGE- MENT STANDARDIZATION PRACTICE MODEL}

In knowledge economy environment, innovation ability has been increased to enterprise's core competitiveness. As the main content of the intellectual property strategy, the patent application, utilization, protection and authorized play a vital role on SME healthy and rapid development. Internationally, it usually divides the whole process of IPR management into three parts, including corporate culture, external support and management entities. Management entities also can divide into three parts, including strategic layer, support layer and practice [8]. Based on the country "standard of enterprise intellectual property management", under the guidance of the main parts around intellectual property management practices, combined with the domestic SME intellectual property management requirements, this paper sets up the basic model of intellectual property management standardization system, specific as follows in Fig. (3).

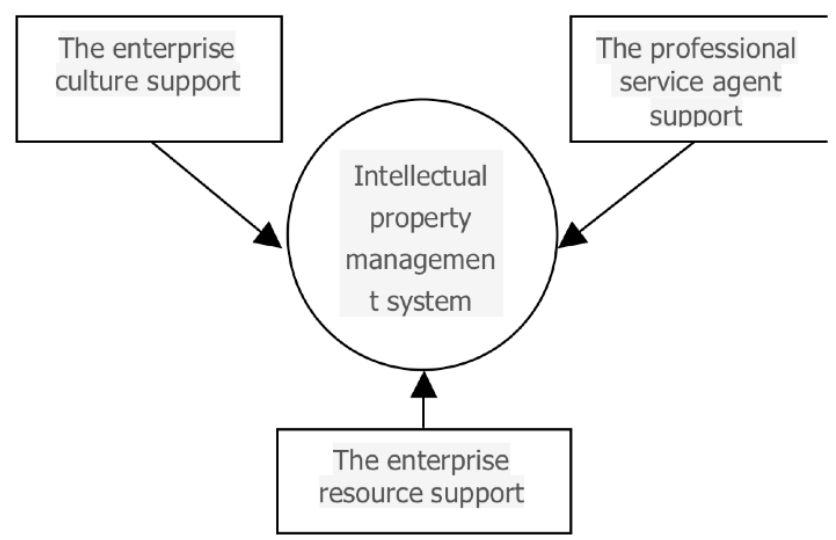

Fig. (3). SME intellectual property management system model.

\subsection{The Enterprise Culture Support}

The full support of enterprise leadership of intellectual property management. Advocating knowledge property right innovation business philosophy. Working atmosphere consciously to protect IPR.

\subsection{The Professional Service Agent}

The international and domestic intellectual property agency provides information retrieval, query and other services. Intellectual property agency to provide targeted analysis and early warning service. Intellectual property legal affairs agency providing services such as the rights of litigation.

\subsection{The Enterprise Resource Support}

Provide including technical, finance and law support, etc.

\subsection{Intellectual Property Management System Support}

The competent department, working mechanism, etc.

This paper suggests that SME establishs intellectual property management system should get the highest leadership authorization, and be supported by the enterprise culture and enterprise resources, which is the basic guarantee on intellectual property management firstly. Secondly, limited by the enterprise in the development of various resources, it should adjust management behavior rely on relevant IPR institutions which provide professional services, ensure innovation and application of IPR legal.

Meanwhile, the enterprise intellectual property management system must contain more comprehensive system, more perfect process, the ability of faster self check and correction [9], which regulates enterprises in raw materials and equipment procurement, product manufacturing and processing, product research and development and technology improvement, technology cooperation and transfer, marketing and exhibition, technology and products import and export trade effectively in the whole business processes, provides enterprises with ability of systematization and standardization of intellectual property management steady as shown in Fig. (4).

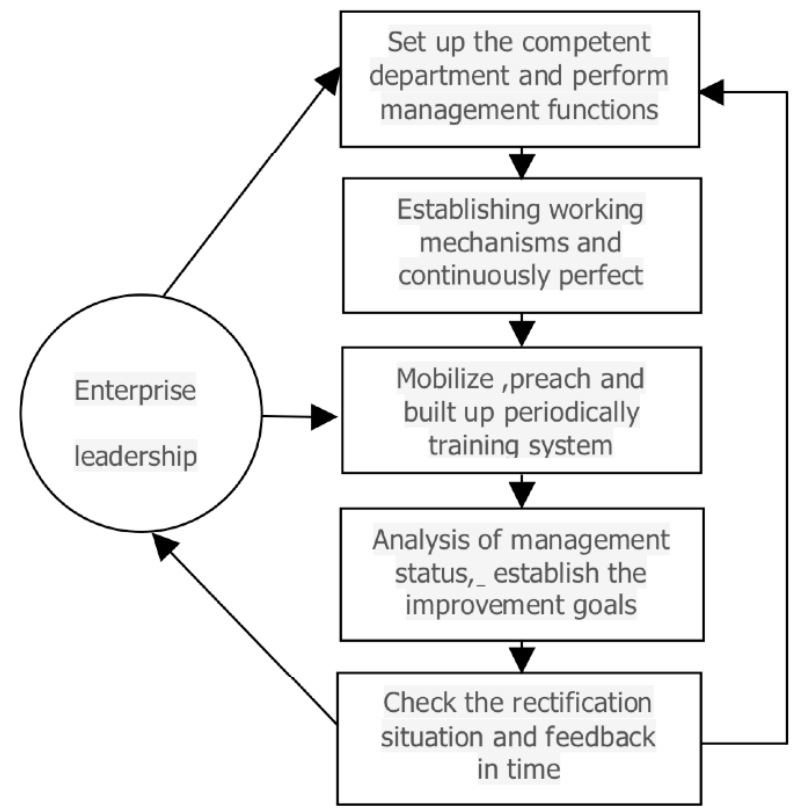

Fig. (4). SME intellectual property management standardization feasible scheme. 
Since "standard of enterprise intellectual property management" was enacted in 2013, it has provided the enterprise intellectual property standardization management with methods, requirements and standards. SME should take standardized demonstration as an opportunity to establish and perfect its own IPR management standardization. The first step, the competent leadership gives authorization to set up the competent department of enterprise intellectual property. Functions includes: organize the formulation of enterprise intellectual property target, system, work plan; the acquisition, use, maintenance of enterprise intellectual property, and other daily management work; internal control of enterprise intellectual property specific implementation; enterprise IPR education and training; the information resources construction, management and utilization of enterprise intellectual property; the management of the enterprise intellectual property management system hiring, internal evaluation, etc. The second step, to establish the working mechanism, and constantly revised. Mainly includes :sort laws and regulations issued by the governments at all levels, and recognized international intellectual property treaties policy assembly; write internal coordination management system, such as project system, such as research and development projects, the examination and approval and management process and internal control system, such as secrecy, system of rewards and punishment system and $\mathrm{r} \& \mathrm{~d}$ activities records, etc. The third step, Mobilize, preach and built up periodically training system. At the first time, the leadership needs to make the mobilization activities of implement standardized, release personnel appointment, management objectives, policies and plans, etc. And preach intellectual property laws, regulations and internal system as the main content to all employees, combining with case impart different jobs employees different intellectual property management experience, to foster the intellectual property management compound talents. The fourth step, analysis management status and set improvement rectification goals. Mainly includes :collect enterprise's record of IPR, information and authorization management files; check whether there is conflict with new laws and regulations, consistent with enterprise development present situation, the scope of protection is clear, or the clause is missing; prepare to appeal in advance for external IPR infringement behavior; make special investigation into various departments, convene symposiums with department manager and staff, and diagnostic analysis summing-up meeting, contrast standard evaluation index system of enterprise's intellectual property management and assessment system for online, forms the enterprise IPR diagnosis of report, puts forward the reasonable rectification opinions, and report to corporate leadership. The fifth step, check the rectification situation and feedback in time. Requirements in accordance with the instruction of the leadership of diagnosis report, coordinate with related departments for rectification, and perfect the system to prevent the rebound problem.

\section{SEVERAL MEASURES TO STRENGTHEN SME INTELLECTUAL PROPERTY ADMINISTRATIVE STANDARDIZATION}

Compare Chinese SME overall ability of IPR management and the management effect with the western developed countries, there is a large gap. Combined with practical investigation, this paper holds that should pay attention to do the following:

(1) Strengthen the management of involving intellectual property personnel. People is the core of innovation and intellectual property management standardization. Companies to take targeted employees properly to do management work. Personnel must be done well before hiring, background investigation, involving other enterprises constraints, the content of the intellectual property to be explicitly stipulated in the contract. Before serving, pre-service education to distinguish internal auditors, technicians, staff members each have emphasize particularly on, plenty of IPR management standardization training. Before leaving, want to have properly after the departure of confidentiality agreement, effective protection enterprise independent IPR.

(2) Strictly enforce the roles in the management of IPR, especially in the process of technology research and development. IPR is standardization of the management object, should be standardized requirements into the whole process of knowledge innovation. On research and development planning, want to rely on information service to the application for the project feasibility report, a holistic analysis, warning of possible law-related intellectual property dispute. In the process of research and development, we will strictly implement the system of internal, clear development technical data and research achievements management requirements, in view of the intellectual property barrier, to make corresponding adjustments in a timely manner. In the whole process of research and development, set up intellectual property management parameter, to the application for project status monitoring, to monitor the annual fee pay, record filing form of intellectual property management. At the same time, want to have a reliable matching management confidentiality system, and only the secret have IPR [10]. Innovation atmosphere and incentive measures, to encourage employees to participate in the intellectual property management. For classification management of IPR, to distinguish the priorities, to ensure that maximize intellectual property management.

(3) Seriously pay attention to writing the intellectual property management standardization manual. Enterprise formulation of "the intellectual property management standardization manual "is to guide employees carry out the work of intellectual property management standard to carry out daily sum, intellectual property management standardization to cover the whole process of enterprise production and operation management, so the enterprise must combine their own actual, highlight the characteristics of streamline, fine management, organization and hard working power standardized operation manual, detailed efforts on intellectual property management standardization department at the end of each link.

\section{SUMMARIZE}

Under the background of vigorously implement the strategy of innovation driven development, Chinese SME's development environment further improvement. The next step, in order to strengthen the use and protection of IPR, the government will also implement directional patent assistance, 
establish intellectual property court. But in reality, the situation of SME intellectual property management is not optimistic. This paper advises starting from building effective intellectual property management system, setting up scientific management mechanism, perfecting working mechanisms, constantly improving the level of enterprise intellectual property management, promoting with independent IPR of core technology transformation and improvement, which will improve enterprise core competitiveness.

\section{CONFLICT OF INTEREST}

The author confirms that this article content has no conflict of interest.

\section{ACKNOWLEDGEMENTS}

Declared none.

\section{REFERENCES}

[1] T. Schoechle, "Re-examining IPR in the context of standardization, innovation and the public sphere", Knowledge, Technology \& Policy, vol.14 (3), pp.109-126, 2001.
[2] B. Kang, and K. Motohashi, "Essential IPR and inventors' involvement in standardization", Research Policy, 2014.

[3] K. Blind, and N. Thumm, "Intellectual property protection and standardization", International Journal of IT Standards and Standardization Research (IJITSR), vol.2, no. 2, 2004.

[4] W. Li, and G. Xie, "Industry strategic management of intellectual property", International Journal of Business and Management, vol. 2 no. 6, 2009

[5] H. Jeremy, M. Stelvia, B. Vernon, and D. Robin, "Commercializing university research in diverse settings: moving beyond standardized intellectual property management”, Research Technology Management, vol. 57, no. 5, pp. 26-34, 2014.

[6] A. O. Laplume, S. Pathak, and E. Xavier-Oliveira, "The politics of IPR regimes: An empirical study of new technology use in entrepreneurship", Technovation, vol. 34, no. 12, 2014

[7] S. A. Kaushik, W. Jonathan, and K Aaron, "The ethics of IPR in an era of globalization", The Journal of law, medicine \& ethics: aAjournal of the American Society of Law, Medicine \& Ethics, vol. 41, no. 4, pp. 841-51, 2014.

[8] D. F. Luckenbill, and S. L. Miller, "Defending intellectual property: State efforts to protect creative works", Justice Quarterly, vol. 15, no. 1, 1998.

[9] Y. Chiu, C.P. Cheng, and W.J. Yang, "IPR and information technology industry development", Journal of Statistics and Management Systems, vol.13, no. 2, pp. 409-428, 2010.

[10] M.L. Liu, X.R. Chang, and Y.Q. Yuan, "On the interrelationship between standardization and IPR of acu-moxibustion therapy", Zhen Ci Yan Jiu, vol. 39, no. 5, pp. 427-430, 2014.

(C) Tang Libo; Licensee Bentham Open.

This is an open access article licensed under the terms of the (https://creativecommons.org/licenses/by/4.0/legalcode), which permits unrestricted, noncommercial use, distribution and reproduction in any medium, provided the work is properly cited. 